\title{
Protein-bound polysaccharide-K augments the anticancer effect of fluoropyrimidine derivatives possibly by lowering dihydropyrimidine dehydrogenase expression in gastrointestinal cancers
}

\author{
EIJI MEKATA ${ }^{1}$, SATOSHI MURATA ${ }^{1}$, HIROMICHI SONODA ${ }^{1}$, TOMOHARU SHIMIZU ${ }^{1}$, TOMOKO UMEDA ${ }^{1}$, \\ HISANORI SHIOMI ${ }^{1}$, SHIGEYUKI NAKA ${ }^{1}$, HIROSHI YAMAMOTO ${ }^{1}$, HAJIME ABE ${ }^{1}$, TAKEO EDAMATSU ${ }^{2}$, \\ AYAKO FUJIEDA $^{2}$, MASAKI FUJIOKA ${ }^{2}$, TSUTOMU WADA ${ }^{2}$ and TOHRU TANI ${ }^{1}$ \\ ${ }^{1}$ Department of Surgery, Shiga University of Medical Science, Seta Tsukinowa-cho, Otsu, Shiga 520-2192; \\ ${ }^{2}$ Biomedical Research Laboratories, Kureha Corporation, Shinjuku, Tokyo 169-8503, Japan
}

Received July 18, 2013; Accepted September 9, 2013

DOI: $10.3892 /$ or.2013.2788

\begin{abstract}
Protein-bound polysaccharide-K (PSK) enhances the antitumor effect of anticancer drug when used clinically in combination with such drugs. PSK is known to act by immunemediated mechanisms; however, the relationship between PSK and metabolic enzymes of anticancer drugs is unknown. We used the collagen gel droplet-embedded culture drug sensitivity test (CD-DST) clinically to evaluate the sensitivity of anticancer drugs. In the present study, we modified the CD-DST by adding peripheral blood mononuclear cells (PBMCs) (immuno-CDDST) and examined the antitumor effect of PSK in combination with anticancer drugs. First, HCT116 human colon cancer cells were cultured with PSK and 5-fluorouracil (5-FU) or 5'-deoxy5 -fluorouridine (5'-DFUR) in the presence or absence of PBMCs, and the antiproliferative effects were compared. In the presence of PBMCs, PSK augmented the inhibitory effects of 5-FU and 5'-DFUR on HCT116 cell proliferation. Next, using human gastric cancer and colon cancer cell lines, the effects of PSK on mRNA expression of various metabolic enzymes of fluoropyrimidines: dihydropyrimidine dehydrogenase (DPD), thymidylate synthase, thymidine phosphorylase and orotate phosphoribosyl transferase, were examined by real-time PCR.
\end{abstract}

Correspondence to: Dr Eiji Mekata, Department of Surgery, Shiga University of Medical Science, Seta Tsukinowa-cho, Otsu, Shiga 520-2192, Japan

E-mail: mekata@belle.shiga-med.ac.jp

Abbreviations: PSK, protein-bound polysaccharide K; CD-DST, collagen gel droplet-embedded culture drug sensitivity test; PBMCs, peripheral blood mononuclear cells; 5-FU, 5-fluorouracil; 5'-DFUR, 5'-deoxy-5-fluorouridine; DPD, dihydropyrimidine dehydrogenase; TS, thymidylate synthase; TP, thymidine phosphorylase; OPRT, orotate phosphoribosyl transferase

Key words: immuno-CD-DST, dihydropyrimidine dehydrogenase, PSK, interferon- $\alpha$, fluoropyrimidine
PSK significantly enhanced DPD mRNA expression in all of the cancer cell lines tested, but not those of the other enzymes. Addition of IFN- $\alpha$ and TRAIL, cytokines known to inhibit DPD expression, to the cultures reduced DPD mRNA expression in the cancer cells. When PBMC samples collected from healthy volunteers were cultured with PSK, IFN- $\alpha$ mRNA expression increased in 3 of the 5 PBMC samples, while TRAIL mRNA expression was unchanged. The present results propose the possibility that PSK induces PBMCs to express IFN- $\alpha$ which inhibits DPD expression, and consequently augments the antitumor effect of 5-FU or 5'-DFUR. Immuno-CD-DST is useful for evaluating drugs with immunological mechanisms of action.

\section{Introduction}

With recent advances in the development of molecular-targeted anticancer agents, it is now possible to identify patients who are likely to respond to treatment and those who are not. For drugs such as cetuximab and Herceptin, pre-treatment tests to examine the expression of various marker molecules have become routine $(1,2)$. Unfortunately, this type of testing is only available for a small number of anticancer drugs. For the majority of cancer chemotherapies, there are no markers to predict response in individual patients, which adds difficulties in designing protocols for clinical trials. In the clinical setting, the explanation for chemotherapy to patients relies mainly on statistical information, which is often not sufficiently convincing. In our department, in order to conduct chemotherapies with patient confidence and plan a precise treatment policy for each patient, we aim at individualized treatment by testing the sensitivity of tumor cells to chemotherapeutic agents using the collagen gel droplet-embedded culture drug sensitive test (CD-DST), a test that simulates physiological conditions. Although the CD-DST may be sufficient to evaluate chemotherapeutic agents alone, in our clinical practice we encounter many patients who are treated with a combination of chemotherapeutic and immunotherapeutic agents such as biological response modifiers (BRMs). 
In these cases, an evaluation method that reflects the immune capability of patients is needed. For this purpose, we modified the CD-DST by adding the peripheral blood mononuclear cells (PBMCs) of patients to the test system and incubating for long periods (designated immuno-CD-DST). Using this method, we attempted to evaluate the effect of combination therapy with BRMs and fluoropyrimidine anticancer agents, and study the effect of BRMs on intra-tumoral enzymes in the presence of PBMCs.

Regarding immunotherapeutic agents, we selected to study protein-bound polysaccharide K (PSK) which is known to be a BMR. PSK has been reported to enhance the effects of anticancer drugs, particularly fluoropyrimidine derivatives, against gastric, colorectal and small cell lung cancer. Currently, PSK is used clinically in Japan and Taiwan. In Japan, the efficacy of combined therapy with PSK and fluoropyrimidine derivatives as postoperative adjuvant therapy for gastric cancer has been reported (3). Clinical trials have also been conducted on colon, rectal (4) and lung cancer (5), and PSK was shown to enhance the effects of fluoropyrimidine derivatives. PSK is a substance extracted from the fungus Coriolus versicolor, and is composed of protein and polysaccharide with a $\beta-1,4$ glucan structure. The approximate molecular weight is $100 \mathrm{kDa}$. Various mechanisms of the antitumor action of PSK have been reported, including immunomodulation (enhancing NK cell, cytotoxic T lymphocyte and lymphokine-activated killer cell activities) and direct damage to cancer cells $(6,7)$. Recent study has shown that PSK acts as a TLR2 agonist to induce immunomodulatory effects (8). However, there is no report on how PSK enhances the effects of fluoropyrimidine derivatives, although the mechanisms of action and metabolic pathways of anticancer agents belonging to the fluoropyrimidine family have been elucidated. Inside the tumor cells, 5-fluorouracil (5-FU) is converted to 5'-fluoro-2'-deoxyuridine by thymidine phosphorylase (TP), and is further converted to 5-fluoro-2'-deoxyuridine 5'-monophosphate by thymidine kinase, consequently inhibiting the DNA synthesizing enzyme thymidylate synthase (TS). Moreover, orotate phosphoribosyl transferase (OPRT) converts 5-FU to 5-fluoro-uridine monophosphate, thereby inhibiting DNA and RNA syntheses. On the other hand, dihydropyrimidine dehydrogenase (DPD) is known to metabolize 5-FU to the inactive form dihydrofluorouracil. Therefore, the lower the activity of DPD, the higher is the activity of 5-FU.

In the present study, we examined whether the addition of PBMCs to the CD-DST alters the antiproliferative effect of PSK combined with 5-FU or 5'-DFUR against tumor cells. Furthermore, focusing on the possible mechanism of how PSK enhances the effect of fluoropyrimidines, we also examined the effect of PSK on the expression of the metabolic enzymes of fluoropyrimidines (DPD, TP, TS and OPRT). The present study reports for the first time the possibility that inhibition of DPD expression by PSK may be a mechanism by which PSK enhances the effect of fluoropyrimidines, as shown experimentally using the immune-CD-DST.

\section{Materials and methods}

Materials. 5-FU was purchased from Kyowa Hakko Kogyo, Co., Ltd. (Tokyo, Japan). 5'-DFUR was a gift from Chugai
Pharmaceutical Co., Ltd. (Tokyo, Japan). PSK was manufactured at Kureha Corp. (Tokyo, Japan) and dissolved in Dulbecco's phosphate-buffered saline (Gibco-BRL, Grand Island, NY, USA). In each experiment, freshly prepared PSK solution was used. Human gastric cancer cell lines (GCIY and MKN45) and human colon cancer cell lines (HCT116 and WiDr) were obtained from ATCC (Manassas, VA, USA). Cells were maintained in RPMI-1640 medium (Gibco-BRL) supplemented with $10 \%$ fetal bovine serum (FBS) (Life Technologies, Milan, Italy) and non-essential amino acids (Sigma, St. Louis, MO, USA). Recombinant IFN- $\alpha$ and TNF $\alpha$ were purchased from Humanzyme Inc. (Chicago, IL, USA) and TRAIL from PeproTech (Rocky Hill, NJ, USA).

Peripheral blood mononuclear cells. Blood donors were selected from healthy volunteers registered at the Department of Surgery, Shiga University of Medical Science, and Biomedical Research Laboratories, Kureha Corp. All donors provided written informed consent. Lymphoprep (Axis-Shield, Oslo, Norway) was used to isolate PBMCs from peripheral blood.

Tumor cell proliferation assay. Tumor cell proliferation assay was conducted using the CD-DST as previously described (9). Briefly, HCT-116 cells were cultured in RPMI-1640 medium supplemented with $10 \% \mathrm{FBS}(10 \% \mathrm{FBS}-\mathrm{RPMI})$ at $37^{\circ} \mathrm{C}$ in a $5 \% \mathrm{CO}_{2}$ atmosphere. Using a Collagen Gel Culture kit (Nitta Gelatin Inc., Osaka, Japan), each cell line was mixed in molten collagen at a final density of $2 \times 10^{5}$ cells $/ \mathrm{ml}$. After solidification, the collagen gel-embedded cells were overlaid with $10 \%$ FBS-RPMI containing 5-FU $(0.3 \mu \mathrm{g} / \mathrm{ml})$ or 5'-DFUR $(3 \mu \mathrm{g} / \mathrm{ml})$, PSK $(0,100$ or $300 \mu \mathrm{g} / \mathrm{ml})$ and PBMCs (none or 4 times the number of cancer cells) and cultured stationarily at $37^{\circ} \mathrm{C}$ in $5 \% \mathrm{CO}_{2}$ atmosphere for $144 \mathrm{~h}$. At the end of the incubation, Neutral red was added to each well at a final concentration of $50 \mu \mathrm{g} / \mathrm{ml}$, and colonies of HCT-116 cells in the collagen gel droplet were stained for $2 \mathrm{~h}$. The cells were then fixed with $10 \%$ neutral-buffered formalin. Images of the stained gel were acquired with a video microscope (VH-5910; Keyence, Osaka, Japan), and the optical density was measured, which indicated the cell proliferation rate. Sensitivity was expressed as $\mathrm{T} / \mathrm{C}(\%)$, where $\mathrm{T}$ is the image optical density of the treated group and $\mathrm{C}$ is that of the control.

\section{Collagen gel culture}

Experiment 1. Expression of fluoropyrimidine metabolic enzymes in tumor cells. Cells were pre-cultured in $10 \%$ FBS-RPMI at $37^{\circ} \mathrm{C}$ in a $5 \% \mathrm{CO}_{2}$ atmosphere. Using a Collagen Gel Culture kit, each cell line was mixed with molten collagen at a final density of $2 \times 10^{5}$ cells $/ \mathrm{ml}$, and then spread on a culture dish ( $\phi=100$ mm; Asahi Glass Co., Ltd., Tokyo, Japan). After solidification, the collagen gel-embedded cells were overlaid with $10 \%$ FBS-RPMI containing PSK $(0,100$ or $300 \mu \mathrm{g} / \mathrm{ml})$ and PBMCs (none or 4 times the number of cancer cells) and cultured stationarily at $37^{\circ} \mathrm{C}$ in a $5 \% \mathrm{CO}_{2}$ atmosphere for $144 \mathrm{~h}$. At the end of the incubation, the culture was treated with $1 \%$ collagenase (Sigma) for $15 \mathrm{~min}$ at $37^{\circ} \mathrm{C}$ and cells were recovered. Total RNA was extracted from the cells using RNeasy Mini kit (Qiagen Inc., Valencia, CA, USA). Messenger RNA expression of fluoropyrimidine metabolic enzymes was measured quantitatively by real-time PCR. 
Table I. Sequences of the primers used in the present study.

\begin{tabular}{|c|c|c|}
\hline Name & Forward & Reverse \\
\hline DPD & 5'-aggacgcaaggagggtttg-3' & 5'-gtccgccgagtccttactga-3' \\
\hline $\mathrm{TP}$ & $5^{\prime}$-agctggagtctattcctggatt-3' & 5'-ggctgcatataggattccgtc-3' \\
\hline TS & 5'-cacactttgggagatgcaca-3' & $5^{\prime}$-ctttgaaagcaccctaaacagccat-3 \\
\hline OPRT & $5^{\prime}$-tcctgggcagatctagtaaatgc-3' & $5^{\prime}$-tgctcctcagccattctaacc-3' \\
\hline IFN- $\alpha$ & $5^{\prime}$-gatctgcctcaaacccacag-3' & $5^{\prime}$-ctggttgccaaactcctcct-3' \\
\hline TRAIL & 5'-caagtcaagtggcaactccg-3' & $5^{\prime}$-gtgagctgctactctctgag-3' \\
\hline GAPDH & $5^{\prime}$-atggggaaggtgaaggtcg-3' & 5'-ggggtcattgatggcaacaata-3' \\
\hline$\beta$-actin & 5'-catccgcaaagacctgtacg-3' & $5^{\prime}$-gatcttcattgtgctgggtgc- $3^{\prime}$ \\
\hline
\end{tabular}

\section{CD-DST}

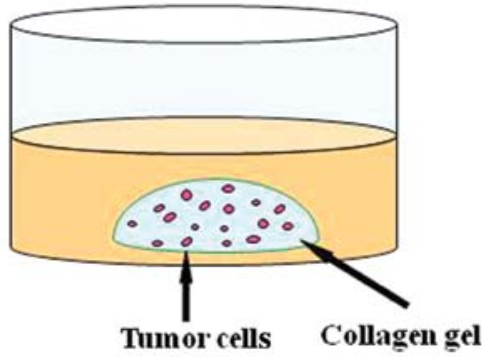

Immuno-CD-DST

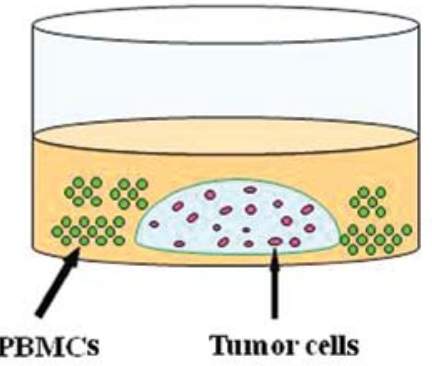

Figure 1. Immuno-CD-DST for evaluation of the sensitivity to anticancer drugs. In the CD-DST, tumor cells are embedded in a collagen gel droplet and cultured in growth medium. In the immuno-CD-DST, tumor cells embedded in a collagen gel droplet are co-cultured with PBMCs suspended in the growth medium.

Experiment 2. Effect of addition of cytokines on DPD expression. Using a Collagen Gel Culture kit, cells were embedded in collagen gel at a final density of $8 \times 10^{5}$ cells $/ \mathrm{ml}$. After solidification, the collagen gel-embedded cells were overlaid with $10 \%$ FBS-RPMI containing various human recombinant cytokines and incubated at $37^{\circ} \mathrm{C}$ in a $5 \% \mathrm{CO}_{2}$ atmosphere for $72 \mathrm{~h}$. At the end of the incubation, collagenase was added to recover the cells from the collagen gel, and total RNA was extracted using FastPure RNA kit (Takara Bio Inc., Shiga, Japan). Messenger RNA expression of cytokines was quantitatively measured by real-time PCR.

Real-time polymerase chain reaction. From the total RNA, cDNA was synthesized using the PrimeScript RT reagent kit (Takara Bio). Using the cDNA as template, real-time PCR was performed with SYBR Premix Ex Taq II (Takara Bio). The quantity of expression of each gene was normalized to that of GUSB, GAPDH or $\beta$-actin gene. The gene expression level was expressed relative to the expression level of the control $(=1)$. The primers used are shown in Table I. The primer for GUSB (HA067813) was purchased from Takara Bio.

Culture of the peripheral blood mononuclear cells. The PBMCs were isolated from 5 healthy volunteers and adjusted to a density of $1 \times 10^{6}$ cells $/ \mathrm{ml}$ in $10 \%$ FBS-RPMI. The cells were incubated at $37^{\circ} \mathrm{C}$ in a $5 \% \mathrm{CO}_{2}$ atmosphere for $24 \mathrm{~h}$. In the PSK-treated group, PBMCs were suspended in $10 \%$ FBS-RPMI containing PSK $(100 \mu \mathrm{g} / \mathrm{ml})$ and cultured in the same manner. At the end of the culture, the cells were recovered by centrifugation, and total RNA was extracted using the FastPure RNA kit (Takara Bio Inc.).

\section{Results}

PSK augments the antiproliferative effect of 5-FU and 5'-DFUR in the presence of PBMCs. We modified the CD-DST that we developed for evaluating the sensitivity of tumors to chemotherapeutic agents (9), by adding PBMCs to the culture system (immuno-CD-DST) (Fig. 1). Using this system, we examined whether addition of PSK, which is known to have an immunomodulatory activity, affects the antitumor effect. The concentrations of 5-FU and 5'-DFUR were the same as used in our previous study using the CD-DST (9). We embedded the human colon cancer cell line HCT116 in collagen, and cultured the collagen gel-embedded cells with PSK and 5-FU or 5'-DFUR in the presence or absence of PMBCs for $144 \mathrm{~h}$. The addition of PSK suppressed cell proliferation both in the presence and in the absence of PBMCs, but the suppression was stronger in the presence of PMBCs. When 5-FU together with PSK were added, the antiproliferative effect was enhanced both in the presence and in the absence of PBMCs, but the effect was the strongest in the presence of PMBCs (Fig. 2A). Likewise, 5'-DFUR showed similar results (Fig. 2B).

PSK reduces DPD $m R N A$ expression in gastrointestinal cells. Based on finding that the antiproliferative effect of 
A

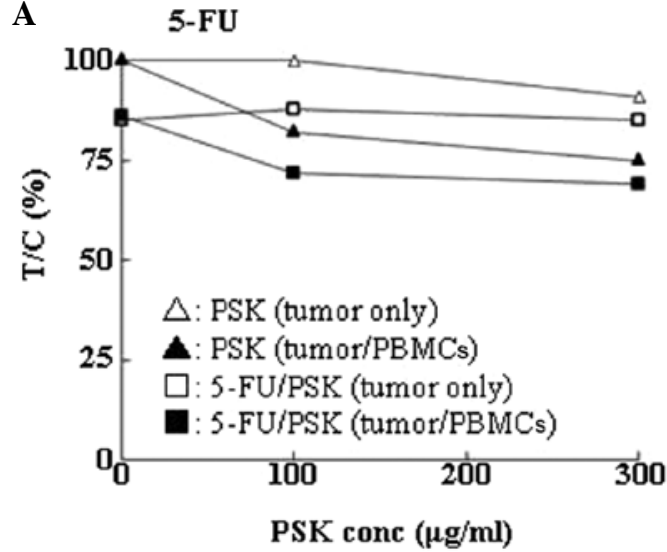

B

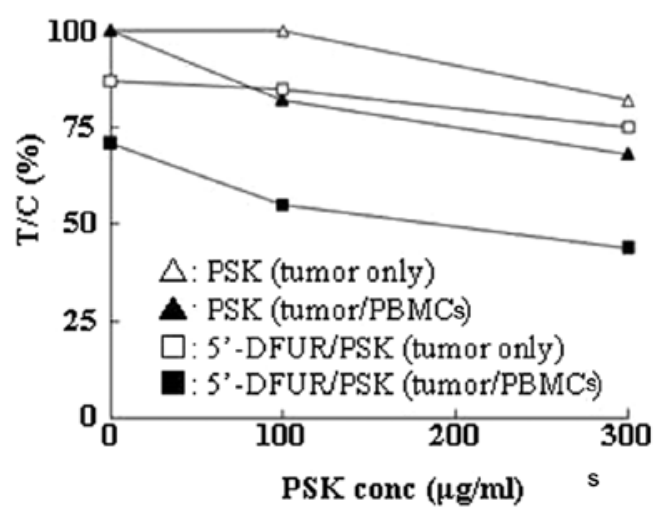

Figure 2. Effects of PSK and/or fluoropyrimidine derivatives on HCT-116 cell proliferation. (A) 5-FU or (B) 5'-DFUR were studied. HCT-116 cells were embedded in collagen gel at a final density of $2 \times 10^{5}$ cells $/ \mathrm{ml}$ and were cultured in growth medium with the addition of 5-FU $(0.3 \mu \mathrm{g} / \mathrm{ml})$ or 5 '-DFUR $(3 \mu \mathrm{g} / \mathrm{ml})$, PSK $(0,100$ or $300 \mu \mathrm{g} / \mathrm{ml})$ and PBMCs (none or 4 times the number of tumor cells) and incubated for $144 \mathrm{~h}$. At the end of the incubation, the collagen gel droplet was stained with Neutral red. Image of the stained gel was acquired with a video microscope and the optical density was measured. Sensitivity was expressed as T/C (\%), where T is the image optical density of the treated group and C is that of the control. $\triangle$, PSK with HCT-116 cells; $\mathbf{\Delta}$, PSK with HCT-116 cells and PBMCs; $\square, 5-F U+P S K$ or 5'-DFUR plus PSK with HCT-116 cells; $\bullet$, 5-FU or 5'-DFUR plus PSK with HCT-116 cells and PBMCs.

A

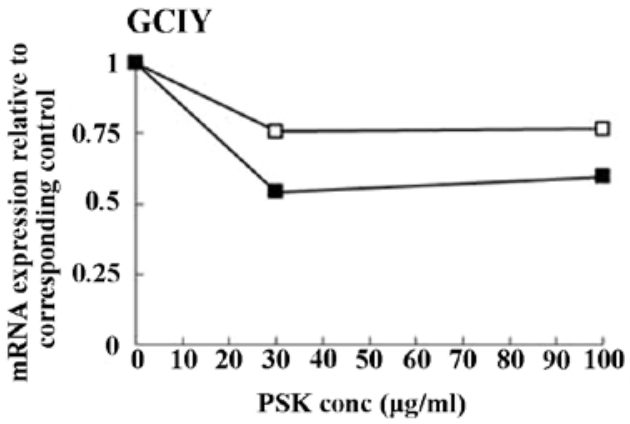

HCT116

C

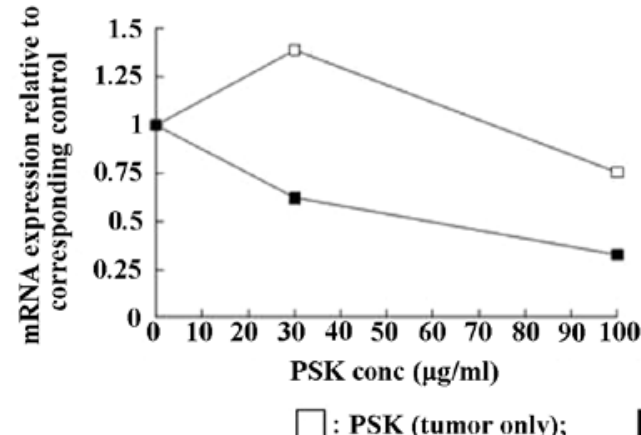

B

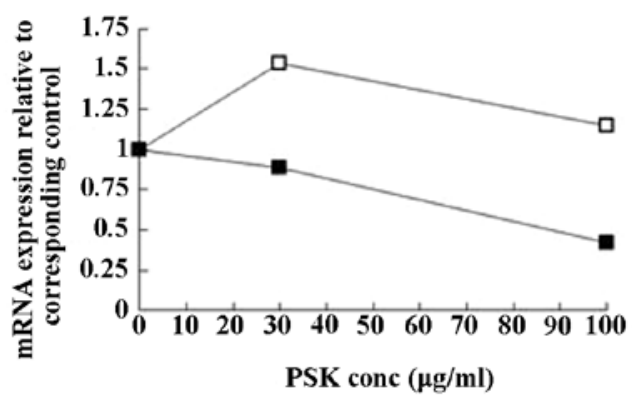

WiDr

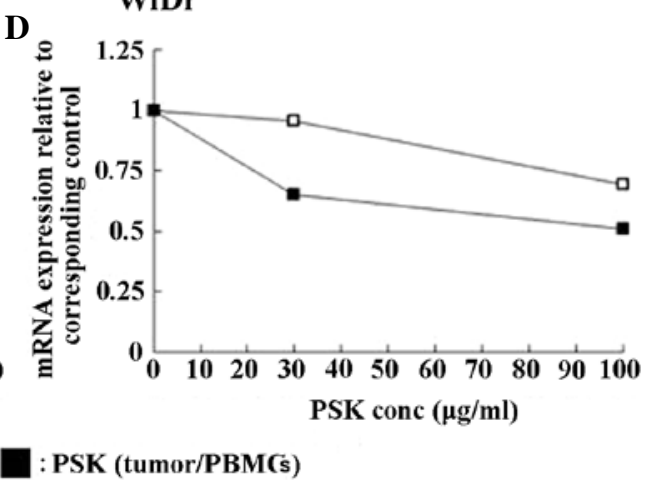

Figure 3. Effects of PSK on dihydropyrimidine dehydrogenase (DPD) mRNA expression in human gastrointestinal cell lines. Human gastric cancer cell lines (A) GCIY and (B) MKN45, and human colon cancer cell lines (C) HCT116 and (D) WiDr were studied. Each cell line was embedded in collagen gel at a final density of $2 \times 10^{5}$ cells $/ \mathrm{ml}$, and cultured in growth medium with the addition of PSK $(0,30$ or $100 \mu \mathrm{g} / \mathrm{ml})$ and PBMCs (none or 4 times the number of tumor cells) and incubated for $144 \mathrm{~h}$. At the end of the incubation, cancer cells were recovered. Total RNA was extracted and subjected to real-time PCR for quantitation of DPD mRNA expression. DPD gene expression was normalized to that of GUSB, and expressed as a ratio relative to the expression level at PSK $0 \mu \mathrm{g} / \mathrm{ml}(=1)$. $\square$, PSK with tumor cells; $\backsim$, PSK with tumor cells and PBMCs.

fluoropyrimidine derivatives is the strongest with the addition of PSK in the presence of PMBCs, we next examined the effects of PMBCs and PSK on the expression of enzymes (DPD, TS, TP and OPRT) associated with the metabolism of fluoropyrimidine derivatives. When collagen gel-embedded gastric cancer cell lines (GCIY and MKN45) and colon cancer cell lines (HCT116 and WiDr) were incubated with PSK, no marked changes in DPD mRNA expression were observed. In contrast, when the collagen gel-embedded cancer cells were incubated with PSK in the presence of PBMCs, DPD mRNA expression was reduced in both the gastric and colon cancer cell lines (Fig. 3). Although no consistent changes in RNA 
A

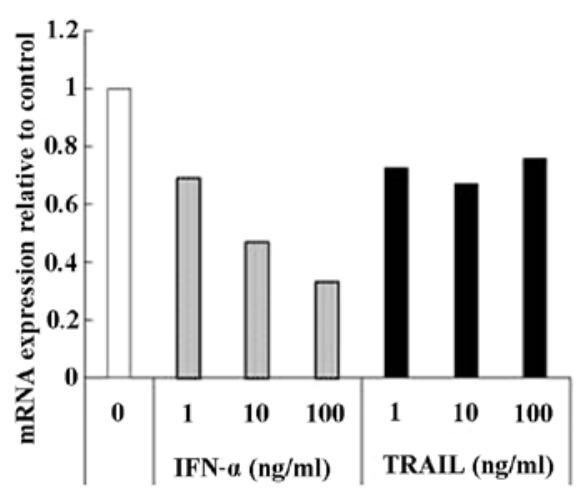

B

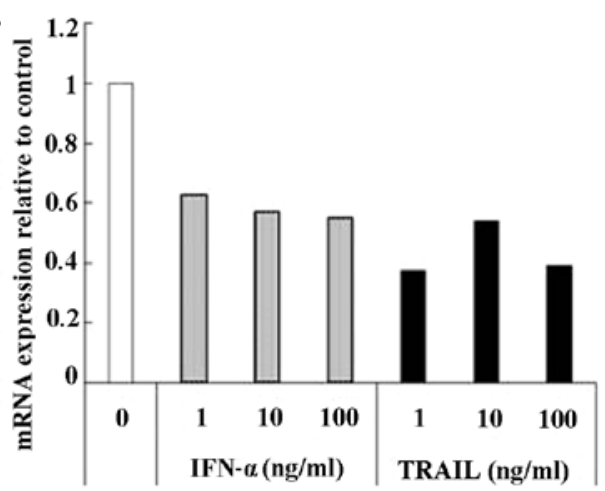

Figure 4. Effects of IFN- $\alpha$ and TRAIL on dihydropyrimidine dehydrogenase (DPD) mRNA expression in human gastrointestinal cell lines. (A) Human gastric cancer cell line GCIY and (B) human colon cancer cell line HCT116 were studied. Cells were embedded in collagen gel at a final density of $8 \times 10^{5}$ cells/ml and cultured in the presence of various concentrations of IFN- $\alpha$ or TRAIL for $72 \mathrm{~h}$. After incubation, cells were recovered. Total RNA was extracted and subjected to real-time PCR for quantitation of IFN- $\alpha$ and TRAIL mRNA expression. Expression of each gene was normalized to that of GAPDH, and expressed as a ratio relative to the expression level of cytokine $0 \mathrm{ng} / \mathrm{ml}(=1)$.

A

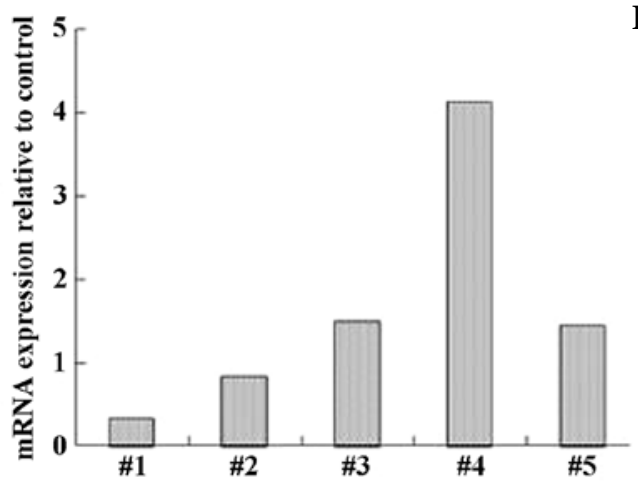

B

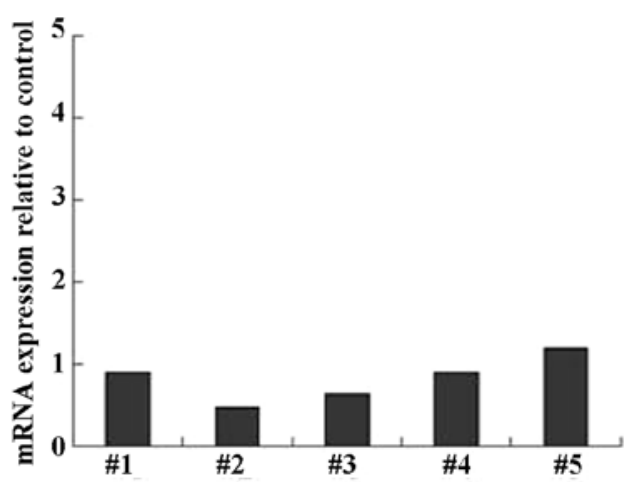

Figure 5. Effect of PSK on (A) INF- $\alpha$ and (B) TRAIL mRNA expression in PBMCs. Peripheral blood mononuclear cells were isolated from 5 healthy volunteers (\#1-\#5), adjusted to a density of $1 \times 10^{6}$ cells $/ \mathrm{ml}$ and incubated for $24 \mathrm{~h}$. PSK ( 0 or $\left.100 \mu \mathrm{g} / \mathrm{ml}\right)$ was added and further incubated. Total RNA was extracted from the cells and subjected to real-time PCR for quantitation of IFN- $\alpha$ and TRAIL mRNA expression. Expression of each gene was normalized to that of $\beta$-actin, and expressed as a ratio relative to the expression level at PSK $0 \mu \mathrm{g} / \mathrm{ml}(=1)$.

expression of the other fluoropyrimidine metabolic enzymes TS, TP and OPRT, were observed by the addition of PSK and PBMCs, TS expression in HCT-116 cells and TP expression in GCIY cells were strongly suppressed (data not shown).

Since the PSK-induced suppression of DPD mRNA expression was consistently lower in the presence of PBMCs than in the absence of PBMCs in all the cell lines examined, we further examined the effect of PSK on DPD expression.

IFN- $\alpha$ and TRAIL reduce DPD mRNA expression in GCIY and HCT-116 cells. IFN- $\alpha$ and TRAIL have been reported to suppress DPD expression in cells $(10,11)$. Using CD-DST, we examined whether addition of these cytokines suppresses DPD expression in GCIY and HCT-116 cell cultures. In both cell lines, DPD expression was reduced by incubation with IFN- $\alpha$ or TRAIL (Fig. 4A and B). Since TRAIL belongs to the TNF- $\alpha$ family, we also examined the effect of TNF- $\alpha$ on DPD expression but observed no changes in DPD mRNA expression (data not shown).

PSK possibly induces IFN- $\alpha$ mRNA expression in PBMCs. Next, we examined whether the expression of IFN- $\alpha$ and TRAIL is induced in PBMCs obtained from healthy volun- teers when cultured in the presence or absence of PSK. IFN- $\alpha$ mRNA expression in PBMCs was increased by 4-fold in 1 of 5 subjects, and by 1.4- to 1.5-fold in 2 of 5 subjects (Fig. 5A). In contrast, TRAIL expression in PBMCs was reduced by 0.5 - to 0.6 -fold in 2 of 5 subjects, with no marked changes (Fig. 5B).

\section{Discussion}

In the present study, we developed an experimental culture model by adding human PBMCs in suspension to collagen gel droplet-embedded cancer cells (immuno-CD-DST), and used this model to examine whether PSK affects the antiproliferative activity of the fluoropyrimidine derivatives, 5-FU and 5'-DFUR. Our results indicated that PSK augmented the effects of both agents. Furthermore, when various cancer cells (human gastric cancer cell lines GCIY and MKN45, and human colon cancer cell lines HCT116 and WiDr) were co-cultured with PBMCs, the addition of PSK reduced DPD mRNA expression. Using hepatocellular carcinoma cells, Oie et al (10) demonstrated that IFN- $\alpha$ inhibited DPD mRNA expression. Moreover, Mizutani et al (11) reported that TRAIL inhibited DPD mRNA expression in renal cell carcinoma. In contrast, Miyazaki et al (12) reported no inhibition of DPD 
mRNA expression when human colon cancer cell lines were incubated with IFN- $\alpha$ and TRAIL. Using the CD-DST system, we cultured GCIY and HCT116 cells with IFN- $\alpha$ or TRAIL and observed decreased DPD mRNA expression. The mechanism by which IFN- $\alpha$ reduces DPD mRNA expression is unknown, but it is important due to its association with increased activity of fluoropyrimidine anticancer agents.

PSK has immunostimulatory actions and has been reported to induce the production of various chemokines and cytokines including TNF- $\alpha$, IL-2 and IL-8 $(8,13,14)$. Kitani et al $(15)$ reported that PSK enhanced polyinosinic:polycytidylic acid (poly I:C)-induced IFN production. When we incubated PBMCs obtained from healthy subjects with PSK, increased IFN- $\alpha$ mRNA expression was observed in 3 of the 5 subjects examined. This result suggests that PSK-induced IFN- $\alpha$ expression in PBMCs may contribute to decreased DPD expression in tumor cells. In order to verify this hypothesis, more studies such as concerning the IFN- $\alpha$ protein expression in PBMCs are necessary, and these have to be conducted using a large number of subject to allow statistical analysis. The present study focused on DPD and further studies are ongoing to elucidate the role of IFN- $\alpha$.

Since human cancer cells were examined in the present study, we used human PBMCs in the test system. Due to the limited number of PBMCs available, we were not able to test multiple samples in each experiment. We, thus, repeated the same experiment at least once to examine whether the results consistently showed the same tendency. As individual differences inevitably exist among PBMCs, as expected, there was variability in the data obtained. However, the same tendency of PSK-induced suppression of DPD mRNA expression in the presence of PBMCs was observed with all 4 cancer cell lines, suggesting a high possibility that PSK inhibits DPD mRNA expression. For TS and TP, reduced expression was observed in some cell lines but not in all. Further studies are required.

Recently, PSK has been reported to be an agonist of TLR2 (8) and TLR4 (16). In general, IFN- $\alpha$ production is considered to be triggered by TRL3, 7 and 9 (17). Recent studies have reported that IFN- $\alpha$ is induced also by TLR2 $(18,19)$, suggesting a possibility that PSK induces IFN- $\alpha$ production via TLR2. On the other hand, PSK had no effect on TRAIL expression. There are no reports of the effects of cytokines other than IFN- $\alpha$ and TRAIL on DPD expression. The question of how various cytokines affect fluoropyrimidine metabolic enzymes is of great interest.

The clinical effect of combined 5-FU and IFN- $\alpha$ therapy remains controversial $(20,21)$. In the study of Nagano et al (20), patients with resectable hepatocellular carcinoma (HCC) and portal vein invasion (Vp3) treated with IFN- $\alpha / 5-\mathrm{FU}$ as postoperative adjuvant therapy had more favorable 1- and 3-year disease-free and overall survival compared to patients not treated with IFN- $\alpha / 5$-FU. On the other hand, Nagano et al (20) pointed out controversial results that IFN- $\alpha$ alone and IFN- $\alpha$ / doxorubicin combination had no effect on the treatment of $\mathrm{HCC}$, and IFN- $\alpha / 5-\mathrm{FU}$ combined chemotherapy yielded a marked effect compared to 5-FU monotherapy. Their report suggests that it is possible that IFN- $\alpha$ exerts some influence on the antitumor effect of fluoropyrimidines. One possible mechanism may be the suppression of DPD expression resulting in enhancement of the antitumor effect of fluoropyrimidines.
In randomized control trials on gastric cancer (3) and colorectal cancer (4), PSK when used with oral 5-FU or tegafur/uracil improved the 5-year disease-free survival compared to the monotherapy of each agent. Apart from the immunomodulatory effect, PSK has been reported to ameliorate an immunosuppressive state and to act directly on tumors inducing apoptosis and suppressing proliferation $(6,7)$, suggesting that these complementary functions are associated with the beneficial effect observed in combination therapy. The present study results suggest that the cytokines induced by PSK act on the metabolic enzymes of fluoropyrimidines resulting in enhancement of the antitumor effect, proposing a novel mechanism of action of PSK that has not been reported hitherto. Combination of PSK and fluoropyrimidine derivatives is very useful as a therapeutic regimen that augments the effects of chemotherapy.

In conclusion, using the novel immuno-CD-DST to co-culture collagen gel-embedded tumor cells with suspended human PBMCs, we examined how PSK affects the antitumor effect of 5-FU and 5'-DFUR against gastrointestinal tumor cells. PSK enhanced the antitumor proliferative effects of 5-FU and 5'-DFUR. In studies concerning the effect of PSK on fluoropyrimidine metabolic enzymes, PSK was found to lower DPD mRNA expression. Further experiments suggest that IFN- $\alpha$ may inhibit DPD gene expression in tumor cells, and PSK may induce IFN- $\alpha$ production by PBMCs. The results obtained from the immuno-CD-DST propose the possibility that PSK acts on immunocompetent cells and induces cytokines that inhibit DPD gene expression to augment the antitumor effect of fluoropyrimidine derivatives. ImmunoCD-DST is potentially useful as an evaluation tool for drugs with immune-mediated effects. Further validation of this system is warranted.

\section{Acknowledgements}

The present study was conducted at the Shiga University of Medical Science, Shiga, Japan and Kureha Corp., Tokyo, Japan.

\section{References}

1. Prenen H, Tejpar S and Cutsem EV: New strategy for treatment of KRAS mutant metastatic colorectal cancer. Clin Cancer Res 16: 2921-2926, 2010.

2. Chang HR: Trastuzumab-based neoadjuvant therapy in patients with HER2-positive breast cancer. Cancer 116: 2856-2867, 2010.

3. Nakazato H, Koike A, Saji S, Ogawa N and Sakamoto J: Efficacy of immunochemotherapy as adjuvant treatment after curative resection of gastric cancer. Lancet 343: 1122-1126, 1994.

4. Ohwada S, Ikeya T, Yokomori T, Kusaba T, Roppongi T, Takahashi T, Nakamura S, Kakinuma S, Iwazaki S, Ishikawa H, Kawate S, Nakajima T and Morishita Y: Adjuvant immunochemotherapy with oral tegafur/uracil plus PSK in patients with stage II or III colorectal cancer: a randomized controlled study. Br J Cancer 90: 1003-1010, 2004.

5. Konno K, Motomiya M, Oizumi K, Sato M, Yamamoto F, Tamiya K, Hasuike T, Yokosawa A, Uchiyama T, Ogawa N and Nakai Y: Effects of protein-bound polysaccharide preparation (PSK) in small cell carcinoma of the lung. Lung Cancer 28: 19-28, 1988.

6. Tsukagoshi S, Hashimoto Y, Fujii G, Kobayashi H, Nomoto $\mathrm{K}$ and Orita K: Krestin (PSK). Cancer Treat Rev 11: 131-155, 1984. 
7. Maehara Y, Tsujitani S, Saeki H, Oki E, Yoshinaga K, Emi Y, Morita M, Kohnoe S, Kakeji Y, Yano T and Baba H: Biological mechanism and clinical effect of protein-bound polysaccharide $\mathrm{K}$ (KRESTIN ${ }^{\circledR}$ ): review of development and future perspectives. Surg Today 42: 8-28, 2012.

8. Lu H, Yang Y, Gad E, Wenner CA, Chang A, Larson ER, Dang Y, Martzen M, Standish LJ and Disis ML: Polysaccharide krestin is a novel TLR2 agonist that mediates inhibition of tumor growth via stimulation of CD8 T cells and NK cells. Clin Cancer Res 17: 67-76, 2011.

9. Okumura K, Mekata E, Shiomi H, Naitoh H, Abe H, Endo Y, Kurumi Y and Tani T: Expression level of thymidylate synthase mRNA reflects 5-fluorouracil sensitivity with low dose and long duration in primary colorectal cancer. Cancer Chemother Pharmacol 61: 587-594, 2008.

10. Oie S, Ono M, Fukushima H, Hosoi F, Yano H, Maruyama Y, Kojiro M, Terada T, Hirano K, Kuwano M and Yamada Y: Alteration of dihydropyrimidine dehydrogenase expression by IFN- $\alpha$ affects the antiproliferative effects of 5-fluorouracil in human hepatocellular carcinoma cells. Mol Cancer Ther 6 : 2310-2318, 2007

11. Mizutani Y, Nakanishi H, Yoshida O, Fukushima M, Bonavida B and Miki T: Potentiation of the sensitivity of renal cell carcinoma cells to TRAIL-mediated apoptosis by subtoxic concentrations of 5-fluorouracil. Eur J Cancer 38: 167-176, 2002.

12. Miyazaki K, Shibahara T, Sato D, Uchida K, Suzuki H, Matsui H, Yanaka A, Nakahara A and Matsuzaki Y: Influence of chemotherapeutic agents and cytokines on the expression of 5 -fluorouracil-associated enzymes in human colon cancer cell lines. J Gastroenterol 41: 140-150, 2006.

13. Hirose K, Zachariae C, Oppenheim J and Matsusima K: Induction of gene expression and production of immunomodulating cytokines by PSK in human peripheral blood mononuclear cells. Lymphokine Res 94: 475-483, 1990.

14. Asai H, Iijima H, Matsunaga K, Oguchi $Y$, Katsuno $H$ and Maeda K: Protein-bound polysaccharide K augments IL-2 production from murine mesenteric lymph node $\mathrm{CD} 4^{+} \mathrm{T}$ cells by modulating $\mathrm{T}$ cell receptor signaling. Cancer Immunol Immunother 57: 1647-1655, 2008.
15. Kitani H, Trsuru S, Oka M and Zinnaka Y: Effect of immunomodulator PSK on the production of interferon in tumor-bearing mice. J Natl Def Med Coll 6: 30-35, 1981.

16. Price LA, Wenner CA, Sloper DT, Slaton JW and Novack JP Role of toll-like receptor 4 in TNF-alpha secretion by murine macrophages in response to polysaccharide Krestin, a Trametes versicolor mushroom extract. Fitoterapia 81: 914-919, 2010.

17. Trinchieri G: Type I interferon: friend or foe? J Exp Med 207: 2053-2063, 2010

18. Lijeroos M, Vuolteenaho R, Rounioja S, Henriques-Normark B, Hallman M and Ojaniemi M: Bacterial ligand of TLR2 signals Stat activation via induction of IRF1/2 and interferon- $\alpha$ production. Cell Signal 20: 1873-1881, 2008 .

19. Barbalat R, Lau L, Locksley RM and Barton GM: Toll-like receptor 2 on inflammatory monocytes induces type I interferon in response to viral but not bacterial ligands. Nat Immunol 10: 1200-1207, 2009

20. Nagano H, Sakon M, Eguchi H, Kondo M, Yamamoto T, Ota H, Nakamura M, Wada H, Damdinsuren B, Marubashi S, Miyamoto A, Takeda Y, Dono K, Umeshita K, Nakamori S and Monden M: Hepatic resection followed by IFN- $\alpha$ and 5-FU for advanced hepatocellular carcinoma with tumor thrombus in the major portal branch. Hepatogastroenterology 54: 172-179, 2007.

21. Kornmann M, Staib L, Wiegel T, Kreuser ED, Kron M, Baumann W, Henne-Bruns D and Link KH: Adjuvant chemoradiotherapy of advanced resectable rectal cancer: results of a randomized trial comparing modulation of 5-fluorouracil with folic acid or with interferon- $\alpha$. Br J Cancer 103: 1163-1172, 2010 . 